there is a greater impurity of $\mathrm{X}$ than there is in specimen $\mathrm{B}$, or there is a greater impurity in specimen $\mathrm{Y}$ of article A than there is in specimen $Z$, and so on. The statements were not absolute, but they were relative, and being relative they were certainly a very great advance on anything which had been $d$ me before, because until this question of longs and shorts was introduced it was almost impossible to see how to eliminate impurities.

There was another matter: it was easy to determine the behaviour of compound bodies under the action of heat by such a method. For instance, if we took the salts of calcinm, or of strontium, salts which have as perfect and as complete spectra of their own as iron itself-if we heated them properly, tbat is to say, if we did not employ too high a temperature, and did not give them a chance of oxidising, it was exceedingly easy to see how these would behave when the heat was gradually increased, and it was then found that the longest line of the metal was always the one which showed itself first. In fact the metal always behaved as an impurity, and brought out this longest line first, in exactly the way that the smallest quantity of impurity would do. Those are small examples of the work which was done, in the one case by working at a constant temperature, and in the other case by working at varying temperatures; and you see it was possible in this way to prepare maps in which all the various impurities of one substance in another may be eliminated. A diagram will explain the way in which this new knowledge could be utilised. We have, for instance, a great number of photographs of iron, cerium, vanadium, and a great number of other chemical elements. We have compared the spectrum of each of the chemical elements with all the others, compared the lines of iron with cerium, titanium, and so on. The question now is, Given these photographs bristling with impurities-for if there were no impurities present in these photographs we should not know that our photograph was a good one--how are we to prodnce a map which shall be absolutely purified, in which none of these impurities shall have any effect? This diagram (Fig. 26) will show the process which was rendered possible by this long and short series of observations. We have there mapped three spectra, with their long and short lines. We have compared $A$ with $B$, and we find that in the photograph which gives us $A$ compared with $B$ we have so many lines of the two substances. Now we say if $\mathrm{B}$ exists in $\mathrm{A}$ as an impurity, the longest line of $\mathrm{B}$ will be there. We look for the longest line of $B$, and we find it, and we put a minus sign over that line in A to show it is most probably due to an impurity of $\mathrm{B}$. We then ask if there is any more $\mathrm{B}$ in $\mathrm{A}$, and we naturally look for the next longest line of B; we find that, and we put a minus sign over that, and then we look for the next longest line, and mark that; then we look for the next one-it is not there-then there is no more of $\mathrm{B}$ in $\mathrm{A}$. In that way, if we knew everything, we should years ago have been able to determine a spectrum of a substance A, from which all traces of the spectroscopic effects due to the presence of a substance $\mathrm{B}$, had been eliminated, and we might go on with substance $C$, and so on, and in that way eliminate the effects of $\mathrm{C}$ as well as $\mathrm{B}$ from the substance $\mathbf{A}$.

I am the more anxious to insist on this work because I shall

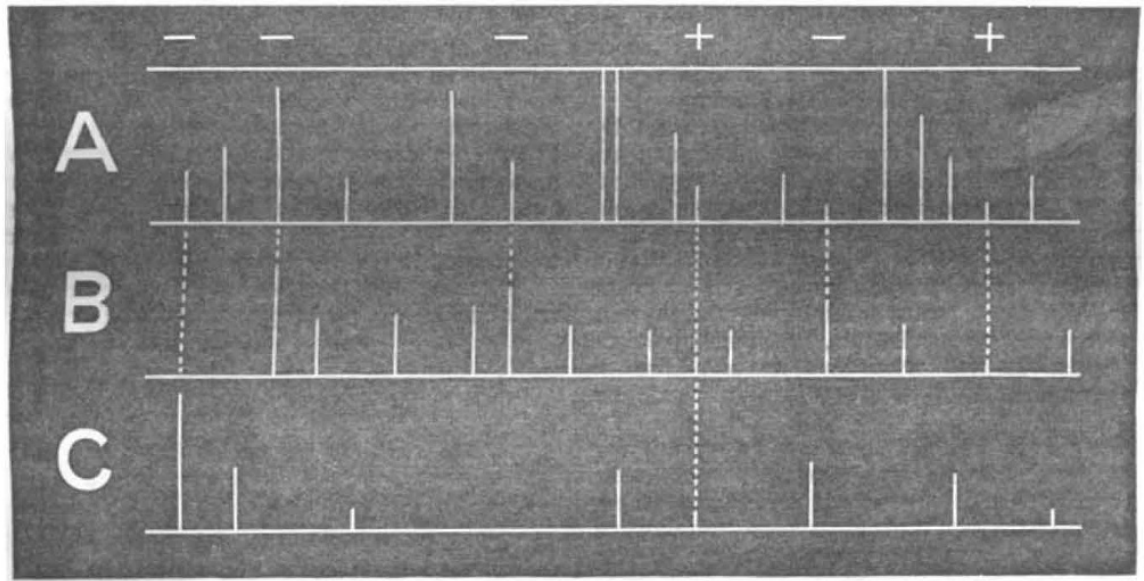

FiG. 26.-Diagram showing the process by which impurities are eliminated from spectra. The lines marked - are due to impurities of one substance in another; those marked + are common or basic lines.

have to show subsequently that it took a very long time to execute it ; that the work is of a very rigid nature; and that, so far as I know, no other suggestion has been made with regard to obtaining pure spectra; and of course, if we wish to study the physics of the sun-especially the chemical physics of the sunthe first desideratum, as Kirchhoff saw, and as Ångström saw, and as we all see now, is to have a series of maps absolutely and completely beyond all suspicion.

There is one other question to be referred to. Was the way perfectly clear, taking the work as it stood, four or fiva years ago? Did our chenical theories then explain all the facts which had been gathered by many men in many lands touching this localisation of the solar chemistry? The localisation had depended on using existing maps, whether tainted with impurities or not, observing the lines in all prominences and spots. Was everything, I say, quite clear, let us say, five years ago? I shall have to show that things were by no means at all clear; that any one who took the trouble to bring together all the results which had been obtained up to that time would have found not only that there was a rift in the lute, but that there was a very big one, and that the discord which grew upon one as one went into detail either with regard to the spectrum of the spots or with regard to the spectrum of the prominences, or with regard to the general localisation of the solar layers, was really very much more remarkable than the accord, and that although, of course, an immense deal had been done towards elaborating a view of solar chemistry a great part of which would stand, still there was a great deal which required a considerable amount of attention and a great deal more which suggested that there was still a higher light to be got before we could really face the magnificent problem with which we are attempting to grapple.

(To be continued.)

J. NORMAN LOCKyer

\section{ANCHOR ICE}

I $N$ an address recently delivered at the Annual Convention of the American Society of Civil Engineers in Montreal, Mr. James B. Francis, the President, gave, inter alia, the results of his observations, during forty years, of anchor ice. The following is the passage in question:-

A frequent inconvenience in the use of water-power in cold climates is that peculiar form of ice called anchor or ground ice. It adheres to stones, gravel, wood, and other substances forming the beds of streams, the channels of conduits, and orifices through which water is drawn; sometimes raising the level of watercourses many feet by its accumulation on the bed, and entirely closing small orifices through which water is drawn for industrial purposes. I have been for many years in a position to observe its effects and the conditions under which it is formed.

The essential conditions are, that the temperature of the water is at its freezing-point, and that of the air below that point; the surface of the water must be exposed to the air, and there must be a current in the water.

The ice is formed in small needles on the surface, which 
would remain there and form a sheet if the surface were not too much agitated, except for a current or movement in the body of water sufficient to maintain it in a constant state of intermixtrure. Even when flowing in a regular channel there is a continued interchange of position of the different parts of a stream, the retardation of the bed caused variations in the velocity which produce whirls and eddies and a general instability in the movement of the water in different parts of the section. The result being that the water at the bottom soon finds its way to the surface, and the reverse. I found by experiments on straight canals in earth and masonry that coloured water discharged at the bottom reached the surface at distances varying from ten to thirty times the depth.

In natural watercourses, in which the beds are always more or less irregular, the disturbance would be much greater. The result is that the water at the surface of a running stream does not remain there, and when it leaves the surface it carries with it the needles of ice, the specific gravity of which differs but little from that of the water, which combined with their small size, allows them to be carried by the currents of water in any direction. The converse effect takes place in muddy streams. The mud is apparently held in suspension, but is only prevented from subsiding by the constant intermixture of the different parts of the stream; when the current ceases the mud sinks to the bottom; the earthy particles composing it, being heavier than water, would sink in still water in times inversely proportional to their size and specific gravity. This, I think, is a satisfactory explanation of the manner in which the ice formed at the surface finds its way to the bottom; its adherence to the bottom, I think, is explained by the phenomenon of regelation first observed by Faraday; he found that when the wetted surfaces of two pieces of ice were pressed together they froze together, and that this took place under water even when above the freezing point. Prof. James D. Forbes found that the same thing occurred by mere contact without pressure, and that ice would become attached to other substances in a similar manner. Regelation was observed by these philosophers in carefully arranged experiments with prepared surfaces fitting together accurately and kept in contact sufficiently long to allow the freezing together to take place. In nature these favourable conditions would seldom occur in the masses of ice commonly observed; but we must admit, on the evidence of the recorded experiments, that under particular circumstances pieces of ice will freeze together or adhere to other substances in situations where there can be no abstraction of heat.

When a piece of ice of considerable size comes in contact under water with ice or other substance it would usually touch in an area very small in proportion to its mass, and other forces acting upon it and tending to move it would usually exceed the freezing force, and regelation would not take place. In the minute needles formed at the surface of the water the tendency to adhere would be mich the same as in larger masses touching at points only, while the external forces acting upon them would be extremely small in proportion, and regelation would often occur, and of the immense number of the needles of ice formed at the surface enough wonld adhere to produce the effect which we observe and call anchor-ice. The adherence of the ice to the bed of the stream or other objects is always down stream from the place where they are formed; in large streams it is frequently many miles below ; a large part of them do not become fixed, but as they come in contact with each other, regelate and form spongy masses, often of considerable size, which drift along with the current and are often troublesome impediments to the use of water-power.

Water-powers supplied directly from ponds or rivers or canals frozen over for a long distance immediately above the places from which the water is drawn, are not usually troubled with anchor-ice, which, as I have stated, requires open water up stream for its formation.

UPON A MODIFICATION OF WHEATSTONE'S MICROPHONE AND ITS APPLICABILITY TO RADIOPHONIC RESEARCHES ${ }^{2}$

IN August, I880, I directed attention to the fact that thin disks or diaphragms of various materials become sonorous when exposed to the action of an intermittent beam of sunlight,

I Paper clx. in the Transactions of the Society, 1878 . Vol. vii., pages sog, 168 .

A paper read before the Philosophical Society of Washington, D.C., Iune $1 x, 188 x$, by Prof. Alex. Graham Bell. and I stated my belief that the sounds were due to molecular disturbances produced in the substance composing the diaphragm (Amer. Assoc. for Advancement of Science, August 27, 1880). Shortly afterwards Lord Rayleigh undertook a mathematical investigation of the subject, and came to the conclusion that the audible effects were caused by the bending of the plates under unequal heating (NATURE, vol. xxiii. p. 274). This explanation has recently been called in question by Mr. Preece (Royal Society, March 10, I88I), who has expressed the opinion that although
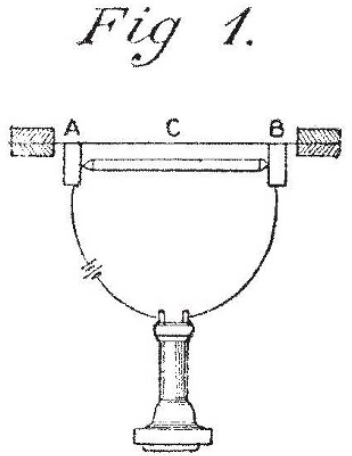

A B, Carbon supports; c, Diaphragm.

vibrations may be produced in the disks by the action of the intermittent beam, such vibrations are not the cause of the sonorous effects observed. According to him the aeerial disturb. ances that produce the sound arise spontaneously in the air itself by sudden expansion due to heat communicated from the diaphragm, every increase of heat giving rise to a fresh pulse of air. Mr. Preece was led to discard the theoretical explanation of Lord Rayleigh on account of the failure of experiments undertaken to test the theory.

$\mathrm{He}$ was thus forced-by the supposed insufficiency of the explanation-to seek in some other direction the cause of the

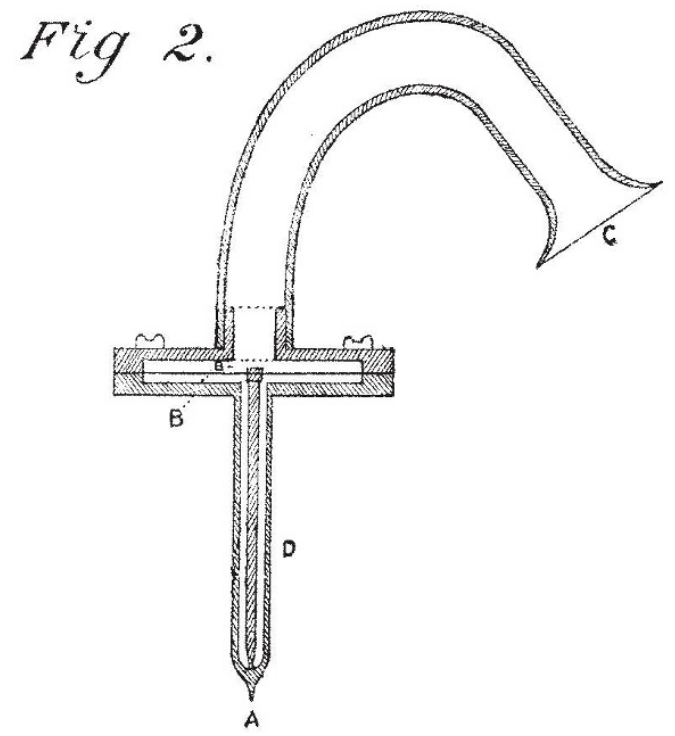

A, Stiff wire; $B$, Diaphragm; C, Hearing tube ; $D$, Perforated handle.

phenomenon observed, and as a consequence he adopted the ingenious hypothesis alluded to above. But the experiments which had proved unsuccessful in the hands of $\mathrm{Mr}$. Preece were perfectly successful when repeated in America under better con. ditions of experiment, and the supposed necessity for another hypothesis at once vanished. I have shown in a recent paper read before the National Academy of Science, April 2I, I88I, that audible sounds result from the expansion and contraction of the material exposed to the beam, and that a real to-and-fro 